\title{
Translocações cromossômicas entre trigo e centeio: uma alternativa ao melhoramento
}

\author{
Chromosomes translocations between wheat and rye: an alternative to plant breeding
}

\author{
Alice Casassola ${ }^{I}$ Sandra Patussi BrammerII
}

\section{- REVISÃO BIBLIOGRÁFICA -}

RESUMO

\begin{abstract}
Translocações são rearranjos cromossômicos estruturais que envolvem segmentos cromossomicos de extensão variada pertencentes a cromossomos homólogos ou não homólogos. Tanto a ocorrência natural quanto a induzida de translocações tem possibilitado um avanço no melhoramento varietal, uma vez que esses segmentos translocados podem carregar genes de resistência a estresses bióticos e abióticos. $O$ centeio é uma espécie da famíla Triticeae muito utilizada para transferência de genes para o trigo como, por exemplo, genes de resistência às ferrugens da folha e do colmo e também genes que favorecem o rendimento, tanto em quantidade como em qualidade de grãos. Assim, o objetivo deste artigo foi o de revisar as principais translocações envolvendo o trigo e o centeio, no qual se verificou, a partir dos dados analisados, que as translocações envolvendo os cromossomos 1 e 2 mostraram-se mais vantajosas para o rendimento de grãos em trigo e que as demais foram importantes, principalmente, na transferência de genes de resistência a estresses. Portanto, essa estratégia tem demonstrado efetividade na busca de novos genes que favorecem o cultivo de trigo e sua utilização vem crescendo grandemente nos últimos anos.
\end{abstract}

Palavras-chave: Triticum aestivum, Secale cereale, rearranjos cromossômicos.

\section{ABSTRACT}

Translocations are structural chromosomal rearrangements which involve segments with different length belonging to homologous or non homologous chromosomes. Either natural or induced occurrence of translocations have been enabled an improvement in the plant breeding, when these translocated segments carry resistance genes to biotic and abiotic stress. Rye is a grass largely used to transfer genes to wheat such as resistance genes to leaf rust, stem rust and genes that support the wheat yield, either in grain quantity or in quality. Thus, the aim of this paper was to review the main translocations involving wheat and rye, which demonstrated, from the data analyzed, that translocations involving chromosomes 1 and 2 were more advantageous for grain yield in wheat and that the others were important, especially, in the transfer of resistance genes. Therefore, this strategy has demonstrated effectiveness on search for new genes that favor the cultivation of wheat and its use has grown greatly in recent years.

Key words: Triticum aestivum, Secale cereale, chromosomal rearrangements.

\section{INTRODUÇÃO}

Translocações cromossômicas são alterações que ocasionam rearranjos estruturais entre cromossomos homólogos ou não homólogos. Segundo BARLOW-STEWART (2007), as translocações podem ser classificadas como simples homozigota, simples heterozigota, recíproca homozigota e recíproca heterozigota. As translocações simples são unidirecionais e as recíprocas bidirecionais; as homozigotas envolvem os dois cromossomos do par de homólogos e as heterozigotas envolvem cromossomos não homólogos.

Translocações Robertsonianas são casos especiais dentre as translocações. Estas envolvem dois cromossomos acrocêntricos em que os pontos de

IFundação Universidade de Passo Fundo (UPF), 99001-970, Passo Fundo, RS, Brasil. E-mail: alicecasassola@yahoo.com.br. Autor para correspondência.

IEmpresa Brasileira de Pesquisa Agropecuária (Embrapa), Passo Fundo, RS, Brasil. 
quebra estão localizados muito próximos ao centrômero, de tal forma que os braços curtos são perdidos e os braços longos se fundem dando origem a um grande cromossomo metacêntrico. Tal tipo de translocação é muito frequente em insetos e em alguns grupos de animais, mas pouco comum em plantas (GUPTA \& GUPTA, 1991).

Dessas translocações, a mais importante nos programas de melhoramento é a translocação heterozigota ou recíproca heterozigota. Esta, geralmente, envolve apenas dois cromossomos, mas, mais raramente, pode envolver três ou mais cromossomos, sendo chamada de translocação complexa. Os translocados heterozigotos têm uma configuração meiótica característica, podendo aparecer conectados, unidos pelas seções translocadas (ZANNETTI \& LAUXEN, 2003). Na fase de paquíteno, os cromossomos pareados assumem uma configuração em cruz. Com a repulsão dos homólogos, a partir do diplóteno, esses cromossomos tendem a assumir a forma de um anel. Na metáfase I, essa forma só se mantém se houver pelo menos um quiasma em cada braço da cruz, caso isso não ocorra, ou haja uma terminalização precoce em um dos braços cromossômicos, o anel se rompe e assume uma configuração idêntica a de um tetravalente em cadeia. $\mathrm{Na}$ anáfase, esses cromossomos podem segregar de várias maneiras, sendo que as formas mais frequentes são: a segregação alternada, a adjacente 1 e a adjacente 2 . Na segregação alternada, ambos os gametas formados são equilibrados. Já na adjacente 1 , em que os centrômeros homólogos se segregam, e na adjacente 2 , em que os centrômeros homólogos seguem para a mesma célula filha, há a produção de gametas não equilibrados. Na segregação alternada, apesar de os gametas serem equilibrados, o centrômero do tetravalente se orienta ao acaso para qualquer um dos pólos, sendo 2/3 dos gametas, provavelmente, inviáveis (GUERRA, 1988). Ou seja, dependendo do tipo de segregação, se alternada, adjacente 1 ou 2 , podese ter gradientes de esterilidade em plantas, pois estas geram gametas não balanceados, contendo duplicações e deficiências, gametas com o mesmo rearranjo translocado do genitor e gametas normais. Este gradiente de esterilidade tem como consequência menos pólens viáveis para cruzamentos direcionados (PAGLIARINI, 2001).

Apesar disso, translocações heterozigotas induzidas são extensamente usadas nos programas de melhoramento de trigo com a finalidade de transferência de genes de resistência a fatores bióticos e abióticos, bem como genes que favorecem o rendimento de grãos. Isso porque raramente a expressão de um gene envolvido no fragmento translocado é alterada quando transferido para um cromossomo não homólogo, efeito conhecido como efeito de posição (GUERRA, 1988).

Linhagens de trigo modificadas podem ser obtidas também por translocações espontâneas, por indução radioativa, cruzamentos, retrocruzamentos, hibridizações de linhagens monossômicas e nulissômicas. Como resultado, pode-se obter híbridos interespecíficos, anfiploides, linhas de adição ou de substituição de cromossomos, além de plantas portadoras de translocações desejáveis (REN \& ZANG, 1997).

Tem-se relatos na literatura de translocações envolvendo diversas espécies de Triticeae como o trigo (Triticum aestivum L.), centeio (Secale cereale L.), cevada (Hordeum vulgare L.) e outras (TAKETA \& TAKEDA, 2001; BARLOY et al., 2007; CHEN et al., 2007; LI et al., 2007). Nesta revisão, serão evidenciadas as translocações envolvendo o trigo e o centeio, com suas vantagens e desvantagens.

\section{DESENVOLVIMENTO}

Embora o trigo de panificação (Triticum aestivum) seja uma espécie poliploide com $2 \mathrm{n}=42$ cromossomos e o centeio (Secale cereale) uma diploide $\operatorname{com} 2 \mathrm{n}=14$, é possível efetuar o cruzamento entre estas e obter um híbrido, o triticale. Este, por ter um genoma instável, apresenta alta taxa de esterilidade. Entretanto, duplicações espontâneas no genoma ou induzidas por agentes químicos como a colchicina, são possíveis. O genoma diploide de trigo é representado por AABBDD (gamético $=A B D$ ), enquanto que o de centeio como RR (gamético=R). Este último possui muitos genes de interesse agronômico, dentre eles pode-se citar o Lr26, $\operatorname{Yr} 19, \operatorname{Pm} 8$ e o $S r 31$, os quais conferem resistência à ferrugem da folha, à ferrugem amarela, ao oídio e à ferrugem do colmo, respectivamente, além de genes que favorecem características agronômicas (KIM et al., 2004; BARTOS et al., 2008).

As translocações mais comuns entre as espécies de trigo e centeio são primeiramente a 1BL.1RS, que envolvem o braço longo (L) do cromossomo 1 do genoma $\mathrm{B}$ de trigo com o braço curto $(\mathrm{S})$ do cromossomo 1 de centeio (R), e a 1AL.1RS. A translocação 1BL.1RS é proveniente de um número pequeno de cultivares de centeio, sendo as principais a 'Aurora' e 'KavKaz' (YANG \& REN, 1997; ZHOU et al., 2004).

O genoma do centeio possui 7.917Mpb e é o maior entre os cereais de clima temperado, sendo que o braço curto do cromossomo $1 \mathrm{R}$ representa somente $5,6 \%$ do genoma do centeio e tem tamanho de $441 \mathrm{Mpb}$, 
o que é comparável ao tamanho do genoma inteiro do arroz (GOFF et al., 2002; YU et al., 2002). BARTOS et al. (2008) estimaram que o segmento $1 \mathrm{R}$ possuiria 1.306.781pb de seu genoma composto por elementos repetitivos da Classe I $(64,3 \%), 100.854 \mathrm{pb}$ de elementos repetitivos da classe II $(5,0 \%), 30.340 \mathrm{pb}$ de elementos não classificados $(1,5 \%), 106.376 \mathrm{pb}$ de outras repetições conhecidas $(5,2 \%)$ e $178.027 \mathrm{pb}$ de outras sequências desconhecidas $(8,8 \%)$. Os mesmos autores identificaram, inclusive, a presença de vários genes no braço curto do cromossomo $1 \mathrm{R}$ como do citocromo $\mathrm{P} 450$, proteína de reparo por excisão XP-D, isoleucina tRNA ligase, proteína quinase R, MLA I, ACC oxidase, proteína de defesa HCBT, cisteína proteinase e tRNAHIS guanililtransferase, estimando a presença de 2.000 genes no 1RS e, aproximadamente, 36.000 genes em todo o genoma. Genes de resistência como $G b 2$, ao greenbug (Schizaphis graminum Rondani) biotipo C, e o $G b 6$, que confere resistência aos biótipos E, I e K, também foram identificados, respectivamente, na cultivar 'Amigo' e na linhagem GRS1201, originária do centeio 'Insave' (PORTER et al., 1994). Têm-se relatos de vários genes de resistência que foram mapeados no $1 \mathrm{RS}$ e que podem ser tranferidos para o trigo via translocação 1BL.1RS. A cultivar 'Petkus', por exemplo, carreia vários genes de resistência a doenças tais como o Sr31 (Puccinia graminis f. sp. tritici), Lr26 (Puccinia triticina Eriks), $\operatorname{Yr} 9$ (Puccinia striiformis Westend) e o Pm8 (Erysiphe graminis f. sp. tritici) (KIM et al., 2004). Além de resistência a estresses bióticos, vários autores sugeriram, inclusive, que translocações com o cromossomos $1 \mathrm{RS}$ tenham efeito positivo no rendimento das plantas, como maior rendimento de grãos, peso de espiga, biomassa e grãos de trigo soft, bem como maior tolerância a estresses e adaptação (Tabela 1).

GRAYBOSCH et al. (1999) observaram que os grãos de trigo soft seriam resultantes de genes presentes no cromossomo $1 \mathrm{R}$ ou no braço $1 \mathrm{RL}$ e que as secalinas de alto peso molecular poderiam interferir na matriz proteica, resultando numa diminuição da dureza dos grãos. Porém, a introdução do gene das secalinas, presentes no braço $1 \mathrm{RS}$ do centeio, no genoma do trigo causa a perda das gliadinas e gluteninas presentes no braço curto do cromossomo 1B do trigo. Essas duas proteínas são componentes do glúten e são as responsáveis pela solubilidade em soluções salinas e pela força e extensibilidade da massa. As gluteninas de alto e baixo peso molecular, respectivamente, $G l u-1$ e $G l u-3$, e as gliadinas, Gli-1, são as mais determinantes na extensibilidade da massa, sendo que a introdução do gene das secalinas no trigo ocasiona a perda destas. Há 15 cópias do gene $S e c-1$ no genoma do centeio (YAMAMOTO \& MUKAI, $2005)$ e este tem alta homologia $(>80 \%)$ com o gene $\omega$ gliadina do trigo (SHIMIZU et al., 1997). GUPTA et al. (1994) relatam que os efeitos da Glu-Dl e Glu-Bl são maiores que da $G l u-A 1$, e por isso as translocações e substituições em 1B e 1D reduzem mais a força da massa. Contudo, YAN et al. (2005) identificaram uma translocação 1BL.1RS com o gene Sec-1, deletado em uma cultivar chinesa de centeio, favorecendo essa translocação.

Apesar de esta translocação apresentar várias contribuições ao melhoramento da planta, estudos têm demonstrado que os genes $\operatorname{Lr} 26, \operatorname{Yr} 19$ e Pm8 não apresentam mais uma proteção completa contra ataques de fungos, uma vez que raças virulentas, como a Ug99, suplantaram a presença do $\mathrm{Yr} 19, \mathrm{Pm} 8 \mathrm{e}$ Sr31, conforme estudos realizados na China (YANG \& REN, 1997; YANG et al. 2003) e na África (PRETORIUS et al., 2000). Além disso, alguns trabalhos relatam efeitos não consistentes da translocação 1BL.1RS em relação ao rendimento. Porém, vários autores destacaram que essas contradições se devem à genealogia do trigo e à interação genótipo x ambiente (VILLAREAL et al., 1998; OWUOCHE et al., 2003; KIM et al., 2004; TANG et al., 2009), sendo que esses fatores devem ser cuidadosamente selecionados para que os resultados sejam favoráveis.

A translocação 1AL.1RS é conhecida por determinar um acréscimo no rendimento de grãos, biomassa, número de espigas por metro quadrado, capacidade de perfilhamento e índice de colheita (OWUOCHE et al., 2003). Desta, as derivadas da cultivar 'Amigo', que, por sua vez, é originária da cultivar 'Insave', são reconhecidas como as melhores para o rendimento (SEBESTA et al., 1995). KIM et al. (2004) relataram que a translocação 1AL.1RS, proveniente da cultivar 'Veery', favoreceria também o rendimento de grãos.

Já a translocação 1DL.1RS apresentou desuniformidade quanto ao rendimento e dependência da cultivar doadora do braço 1RS do centeio (KIM et al., 2004), não apresentando contribuições que justifiquem o seu uso. Essa translocação pode envolver inclusive o braço 1RL do centeio, porém é menos comum e apresenta resultados negativos em relação às características agronômicas, tais como redução no rendimento de farinha (OWUOCHE et al., 2003).

Os híbridos de trigo-centeio podem ser provenientes também da substituição do cromossomo $1 \mathrm{~B}$ do trigo pelo cromossomo $1 \mathrm{R}$ do centeio, sendo este facilmente detectado em preparações citológicas pela presença da região organizadora do nucléolo (RON) e pelas bandas-C teloméricas intensamente 
Tabela 1 - Vantagens e limitações das translocações e substituições envolvendo os cromossomos 1 de Triticum sp. e Secale cereale.

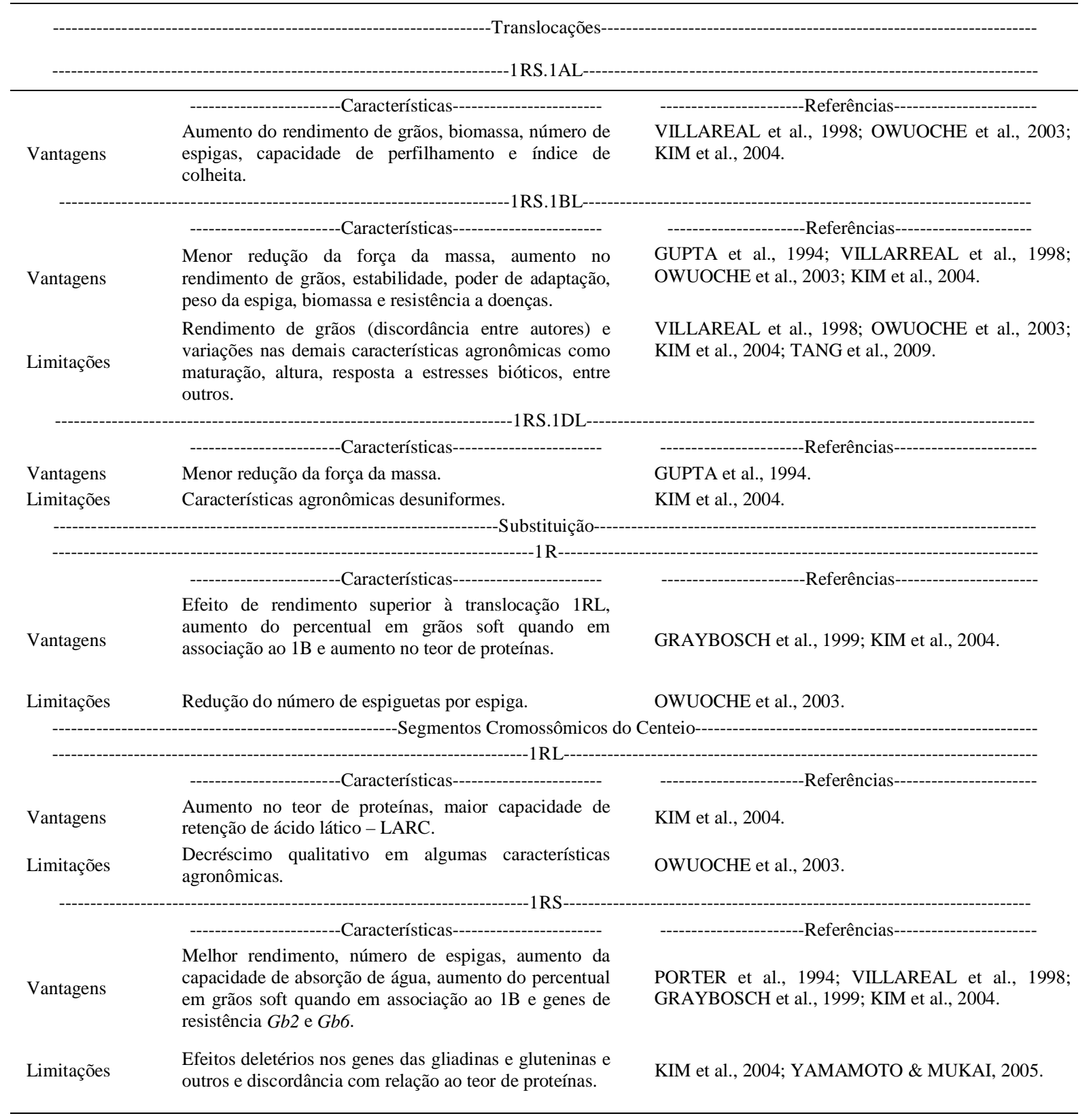

coradas (ANGELOVA \& GEORGIEV, 2006). Quando ocorre essa substituição, há uma redução do número de espiguetas por espiga em comparação à translocação 1BL.1RS, porém aquela apresenta maior densidade de espigas e comprimento de espiga, indicando que o gene que determina o número de espiguetas por espiga e o comprimento da espiga presentes no 1BL.1RS não são expressos na presença do 1AL.1RS (OWUOCHE et al., 2003).

Comparando a substituição $1 \mathrm{R}$ e as translocações envolvendo 1RS e 1RL, tem-se que as translocações com 1RS apresentam maiores efeitos positivos sobre o rendimento de grãos, biomassa, número de espigas e aumento na absorção de água (VILLAREAL et al., 1998; KIM et al., 2004). KIM et al. (2004) relataram, inclusive, que o efeito da translocação $1 \mathrm{RS}$, tanto no genoma A (1RS.1AL), como no B (1RS.1BL) ou no D (1RS.1DL), não apresenta diferença significativa no rendimento de grãos. Ou seja, a translocação 1BL.1RS é melhor e mais vantajosa que a 1AL.1RS, pois, apesar de esta última afetar menos as características de panificação, a anterior apresenta 
maiores vantagens em relação ao rendimento, podendo se minimizar as características indesejáveis geradas desde que a fonte de centeio e de trigo para a translocação sejam cuidadosamente selecionadas. NAGY et al. (2003), por exemplo, demonstraram que é possível introduzir novas variações genéticas, a partir do braço 1R, em trigo, cruzando cultivares comerciais, contendo a translocação 1BL.1RS, com linhagens de triticale, obtidas a partir de genótipos de centeio préselecionados, minimizando assim os efeitos indesejáveis.

Outra estratégia envolvendo translocações entre trigo e centeio refere-se ao uso do cromossomo 2 de ambas as espécies. Os cromossomos 2B e 2R apresentam alta homologia, porém a recombinação entre eles ocorre somente na porção distal destes, sendo que a porção $2 \mathrm{RL}$ é geneticamente equivalente a $2 \mathrm{BL}$, enquanto que a $2 \mathrm{RS}$ é similar tanto a $2 \mathrm{BS}$ como a $6 \mathrm{BS}$, podendo, neste caso, haver perda de dois segmentos distintos, localizados em braços diferentes do trigo (DEVOS et al., 1993).

$\mathrm{O}$ cromossomo $2 \mathrm{~B}$ possui poucos genes relacionados com conteúdo protéico (gliadinas e gluteninas) e, por isso, translocações envolvendo este cromossomo afetam menos as características de panificação (KNACKSTEDT et al., 1994). Já o cromossomo $2 \mathrm{R}$ do centeio apresenta genes de resistência ao oídio e à ferrugem da folha e do colmo (BRUNELL et al., 1999), ao ataque da mosca Hessian (LIU et al., 2005; SARDESAI et al., 2005; ZHAO et al., 2006) e ao nanismo amarelo da cevada (barley yellow dwarf virus - BYDV) (NKONGOLO \& COMEAU, 1998).

Vários genes de resistência à mosca Hessian (Mayetiola destrutor) foram mapeados no cromossomo do centeio 2RL, dentre eles H13, (LIU et al., 2005), H32 (SARDESAI et al., 2005) e H22 (ZHAO et al., 2006). HATCHETT et al. (1993), por exemplo, estudaram o efeito da translocação 2BS.2RL na cultivar 'Hamlet' e verificaram que esta confere resistência ao biotipo L da mosca Hessian, o mais virulento dentre eles. Já HYSING et al. (2007) não verificaram resistência das cultivares em estudo aos genótipos utilizados dessa mosca, indicando ser resultado de, provavelmente, uma variação alélica dos genes de resistência.

Em relação às características agronômicas, EHDAIE et al. (2003) relataram que a presença do cromossomo $2 \mathrm{R}$ do centeio aumentava a eficiência no uso da água disponível no solo e melhorava as características de enraizamento da planta. BOROS et al. (2002) observaram que a presença do 2RL aumentava significativamente a quantidade de arabinoxilanas, importantes para a qualidade nutricional e de cozimento de cereais. EHDAIE et al. (2003) abordaram, inclusive, que a presença da translocação 2BS.2RL diminuia o tempo de maturação e aumentava o número de grãos por espiga, bem como, que a presença da translocação proveniente da linhagem 'Hamlet' no trigo cultivar 'Karl' acrescia o rendimento de grãos, biomassa aérea na maturidade, grãos por espiga, grãos por planta, mas diminuia o período de maturação e o peso do grão. HYSING et al. (2007) complementaram afirmando que esta translocação tinha efeito positivo no rendimento e pouca influência na qualidade de panificação, podendo ser utilizada para transferência de genes de resistência a doenças.

Compararações entre a presença da translocação 2BS.2RL com a 2AS.2RL, demonstraram que a $2 \mathrm{BS} .2 \mathrm{RL}$, proveniente da cultivar de centeio 'Chaupon', reduziu o peso do grão, o rendimento de farinha, a dureza da espiga e a absorção de água. Já a translocação 2AS.2RL, proveniente da cultivar 'Imperial', presente na cultivar 'Chinese Spring', apresentou melhor rendimento de grãos, biossama até a maturação, biomassa da raiz e eficiência no uso da água (KNACKSTEDT et al., 1994; EHDAIE et al., 2003).

HYSING et al. (2007) também avaliaram cultivares provenientes de linhas de substituição ('Holme/Kraka//Holme') de 1B e 2B por, respectivamente, $1 \mathrm{R}$ e $2 \mathrm{R}$. Todas as linhagens foram resistentes a 17 raças isoladas de oídio na germinação e a mistura de raças na fase de planta adulta. Porém, constataram que, em plantas com translocação para esses cromossomos, não havia resistência na fase de plântula à ferrugem amarela, somente em planta adulta. Linhagens com translocações e substituições envolvendo os demais cromossomos destas espécies também têm sido alvo de diversos estudos, como as linhagens com substituições trigocenteio $5 \mathrm{~A} / 5 \mathrm{R}$, as quais apresentaram espigas e aristas maiores, espícula abundante, alto conteúdo protéico, resistência a várias doenças, tolerância à seca, entre outros. Entretanto, como características indesejáveis, estas plantas têm o colmo fraco e baixo rendimento. Já em linhagens com substituição 6A/6R, ficou demonstrada a alta densidade de espigas sem arista, $\mathrm{o}$ alto rendimento, a resistência ao oídio e às ferrugens (ZHANG et al., 1999; LI et al., 2006). Essas linhagens também foram avaliadas em relação à fertilidade, sendo que LI et al. (2006) relataram que, em cruzamentos, os híbridos tiveram fertilidade normal e as linhagens translocadas, a partir de $\mathrm{F}_{2}$ a $\mathrm{F}_{5}$, apresentaram boas características agronômicas. Além disso, os cromossomos 5A e 5R bem como o 6A e o 6R são altamente relacionados, os quais pareiam na ausência de cromossomos homólogos. Os gametas masculinos 
e femininos com o cromossomo 6R do centeio (Secale cereale L.), por exemplo, são transferidos por retrocruzamento em trigo com taxa de transferência $10.8 \%$ e $8.8 \%$, respectivamente (LI et al., 2006).

Recentemente, WEHLING et al. (2003) mapearam o gene de resistência $(P r 2)$ à ferrugem da folha na porção distal do cromossomo 7RL do centeio, o qual está envolvido em translocações espontâneas 7BS/7RL, detectadas por CARVALHO et al. (2009) a partir de marcadores cito-moleculares.

\section{CONCLUSÃO}

As translocações podem ocorrer de maneira natural durante o cruzamento inter ou intraespecífico, bem como podem ser induzidas em laboratório, dependo da finalidade. O centeio é uma espécie passível de translocar segmentos cromossômicos para o trigo e, pelo fato de possuir muitos genes de resistência a estresses, tais como genes de resistência à ferrugem da folha e do colmo e genes que favorecem o rendimento de grãos, vem sendo muito utilizado como doador desses genes em programas de melhoramento. Estes segmentos são transferidos a partir das translocações, pois os cromossomos do trigo tendem a quebrar simultaneamente, resultando na incidência de segmentos pequenos de cromossomos do centeio incorporados no genoma do trigo. Vários genes de interesse já foram efetivamente transferidos do centeio para o trigo a partir de translocações. Dentre as principais que envolvem essas espécies, destaca-se a 1BL.1RS, a qual demonstra importância no que se refere à melhora de rendimento de grãos, seguida pelas demais, no que se refere à transferência de genes de resistência a estresses bióticos, principalmente. Portanto, essa estratégia vem crescendo grandemente durante os anos por ser efetiva na busca de novos genes associados à tolerância/resistência a estresses abióticos e bióticos, principalmente nas patologias em que seus agentes etiológicos se especializam e, consequentemente, "quebram" essa resistência. Porém, essas translocações devem ser selecionadas criteriosamente, pois podem ocasionar certo grau de esterilidade, bem como são dependentes do parental doador e de interações do genótipo com o ambiente.

\section{REFERÊNCIAS}

ANGELOVA, Z.; GEORGIEV, S. Visualization of Secale cereale DNA in wheat germ plasm by genomic in situ hybridization. Biotechnology \& Biotechnological Equipament, v.20, p.2629, 2006. Disponível em: <http://www.diagnosisp.com/dp/journals/ view_pdf.php?journal_id=1\&archive $=0$ \&issue_id=12\&article_id=327>. Acesso em: 20 abr. 2010. ISSN 1310-2818.
BARLOW-STEWART, K. Changes to chromosome structure - Translocations. In: BARLOW-STEWART, K. The Australasian genetics resource book. Autrália: Centre for Genetics Education, 2007. Cap.7, p.1-5. Disponível em: <http:/ /www.genetics.edu.au/pdf/factsheets/fs07.pdf>. Online. Acesso em: 29 out. 2010.

BARLOY, D. et al. Marker-assisted pyramiding of two nematode resistance genes from Aegilops variabilis in wheat. Molecular Breeding, v.20, p.31-40, 2007. Disponível em: <http:// www.springerlink.com/content/2 w12g6753394472 q/ fulltext.pdf>. Acesso em: 25 maio, 2010. doi: 10.1007/s11032006-9070-x.

BARTOS, J. et al. A first survey of the rye (Secale cereale) genome composition through BAC end sequencing of short arm of chromosome 1R. BMC Plant Biology, v.8, p.95-106, 2008. Disponível em: <http://www.springerlink.com/content/ c788650177143n01/fulltext.pdf>. Acesso em: 10 jun. 2010. doi: 10.1186/1471-2229-8-95.

BOROS, D. et al. Chromosome location of genes controlling the content of dietary fibre and arabinoxylans in rye. Euphytica, v.128, p.1-8, 2002. Disponível em: <http:// www.springerlink.com/content/q015373222644415/ fulltext.pdf $>$. Acesso em: 15 abr. 2010. doi: 10.1023/ A: 1020639601959 .

BRUNELL, M.S. et al. Development of arm specific RAPD markers for rye chromosome $2 \mathrm{R}$ in wheat. Crop Science, v.39, p.1702-1706, 1999. Disponível em: <https://www.crops.org/ publications/cs/pdfs/39/6/1702>. Acesso em: 20 abr. 2010. doi: 10.2135/cropsci1999.3961702x.

CARVALHO, A. et al. Identification of the spontaneous 7BS/ 7RL intergenomic translocation in one F1 multigeneric hybrid from the Triticeae tribe. Plant Breeding, v.128, p.105-108, 2009. Disponível em: <http://onlinelibrary.wiley.com/doi/ 10.1111/j.1439-0523.2008.01519.x/pdf>. Acesso em: 12 maio, 2010. doi: 10.1111/j.1439-0523.2008.01519.x.

CHEN, Q.Z. et al. Development and characterization of Triticum aestivum - Haynaldia villosa translocation line T4VS.4VL-4AL. Acta Agronomica Sinica, v.33, p.871-877, 2007. Disponível em: <http://epub.cnki.net/grid2008/docdown/ docdownload. aspx?filename $=$ XBZW200706000\&dbcode $=$ CJFD \&year=2007\&dflag=pdfdown $>$. Acesso em: 21 jun. 2010. doi: CNKI:ISSN:0496-3490.0.2007-06-000.

DEVOS, K.M. et al. Chromosomal rearrangements in the rye genome relative to that of wheat. Theoretical and Applied Genetics, v.85, p.673-680, 1993. Disponível em: <http:// www.springerlink.com/content/v5636477g77h5641/ fulltext.pdf $>$. Acesso em: 13 abr. 2010. doi: 10.1007/ BF00225004.

EHDAIE, B. et al. Root biomass, wateruse efficiency, and performance of wheat-rye translocations of chromosomes 1 and 2 in spring bread wheat 'Pavon'. Crop Science, v.43, p.710-717, 2003. Disponível em: <https://www.crops.org/ publications/cs/pdfs/43/2/710>. Acesso em: 21 jun. 2010. doi: $10.2135 /$ cropsci2003.7100.

GOFF, S.A. et al. A draft sequence of the Rice genome (Oryza sativa L. SSP. japonica). Science, v.296, p.92-100, 2002. Disponível em: <http://www.sciencemag.org/content/296/5565/ 92.full.pdf>. Acesso em: 21 jun. 2010. doi: 10.1126/ science. 1068275 . 
GRAYBOSCH, R.A. et al. Genetic, agronomic and quality comparisons of two 1AL.1RS wheat-rye chromosomal translocations. Plant Breeding, v.118, p.125-130, 1999. Disponível em: <http://digitalcommons.unl.edu/cgi/ viewcontent.cgi? article $=1122 \&$ context $=$ agronomyfacpub \&seiredir $=1$ \#search $=$ "Genetic, + agronomic + and + quality + compa risons+of+two $+1 \mathrm{AL} .1 \mathrm{RS}+$ wheatrye+chromosomal+translo cations.">. Acesso em: 10 ago. 2010. doi: 10.1046/j.14390523.1999.118002125.x.

GUERRA, M. Introdução à citogenética geral. Rio de Janeiro: Guanabara Koogan, 1988. 142p.

GUPTA, R.B. et al. Allelic variation at glutenin subunit and gliadin loci, Glu-1, Glu-3 and Gli-1 of common wheats. I. its additive and interaction effects on dough properties. Journal of Cereal Science, v.19, p.9-17, 1994. Disponível em: <http:/ /dx.doi.org/10.1006/jcrs.1994.1004>. Acesso em: 20 abr. 2010. doi:10.1006/jcrs.1994.1004.

GUPTA, K.P.; GUPTA, S.N. Cytogenetics of chromosome interchanges. In: _-___-_ TSUCHIYA, T. Chromosome engeneering in plants: genetics, breeding, evolution. Amsterdam: Elsevier, 1991. Cap.5, p.87-112.

HATCHETT, J. et al. Inheritance of resistance to Hessian fly in rye and wheat - rye translocation lines. Crop Science, v.33, p.730-734, 1993. Disponível em: <https://www.crops.org/ publications/cs/pdfs/33/4/CS0330040730>. Acesso em: 10 ago. 2010. doi: 10.2135/cropsci1993.0011183X003300040019x.

HYSING, S.C. et al. Agronomic Performance and Multiple Disease Resistance in T2BS.2RL Wheat-Rye Translocation Lines. Crop Science, v.47, p.254-260, 2007. Disponível em: <http:// ddr.nal.usda.gov/bitstream/10113/16043/1/IND43883747.pdf>. Acesso em: 18 jun. 2010. doi: 10.2135/cropsci2006.04.0269.

KIM, W. et al. Agronomic effect of wheat-rye translocation carrying rye chromatin (1R) from different sources. Crop Science, v.44, p.1254-1258, 2004. Disponível em: <http:// ddr.nal.usda.gov/bitstream/10113/8463/1/IND43681410.pdf>. Acesso em: 20 abr. 2010. doi: 10.2135/cropsci2004.1254.

KNACKSTEDT, M.A. et al. Effects of T2BS.2RL wheat - rye translocation on breadmaking quality in wheat. Crop Science, v.34, p.1066-1070, 1994. Disponível em: <https://www.crops.org/ publications/cs/pdfs/34/4/CS0340041066>. Acesso em: 15 abr. 2010. doi:10.2135/cropsci1994.0011183X003400040042x.

LI, J-L. et al. Study on homoeologous chromosome pairing and translocation induced by $5 \mathrm{~A} 5 \mathrm{R} \times 6 \mathrm{~A} 6 \mathrm{R}$ wheat-rye substitution lines. Acta Genetica Sinica, v.33, n.3, p.244250, 2006. Disponível em: <http://dx.doi.org/10.1016/S03794172(06)60047-4>. Acesso em: 20 abr. 2010. doi: 10.1016/ S0379-4172(06)60047-4.

LI, G. et al. Effects of the 6VS.6AL translocation on agronomic traits and dough properties of wheat. Euphytica, v.155, p.305313, 2007. Disponível em: <http://www.springerlink.com/ content/95638518485025j0/fulltext.pdf $>$. Acesso em: 13 abr. 2010. doi: 10.1007/s10681-006-9332-z.

LIU, X.M. et al. Hessian Fly resistance gene H13 is mapped to a distal cluster of resistance genes in chromosome 6DS of wheat. Theoretical and Applied Genetics, v.111, p.243-249, 2005. Disponível em: <http://www.springerlink.com/content/ g77lg225040868ul/fulltext.pdf $>$. Acesso em: 10 jun. 2010. doi: $10.1007 / \mathrm{s} 00122-005-2009-5$.
NAGY, E.D. et al. Genetic mapping of sequence-specific PCRbased markers on the short arm of the $1 \mathrm{RS} .1 \mathrm{BL}$ wheat-rye translocation. Euphytica, v.132, p.243-250, 2003. Disponível em: <http://www.springerlink.com/content/p63207481p2220p1/ fulltext.pdf $>$. Acesso em: 19 ago. 2010. doi: 10.1023/ A: 1025002919746 .

NKONGOLO, K.K.; COMEAU, A. Registration of genetic stock Kivu-85, a wheat-rye substitution line tolerant to the barley yellow dwarf virus (BYDV). Crop Science, v.38, p.1413, 1998. Disponível em: <https://www.crops.org/publications/cs/ pdfs/38/5/CS0380051413>. Acesso em: 20 abr. 2010. doi: 10.2135/cropsci1998.0011183X003800050068x.

OWUOCHE, J.O. et al. Heterotic effects of wheat-rye chromosomal translocations on agronomic traits of hybrid wheat (Triticum aestivum L.) under an adequate moisture regime. Euphytica, v.132, p.67-77, 2003. Disponível em: <http:// www.springerlink.com/content/g w $5552522840 \mathrm{v} 86 /$ fulltext.pdf>. Acesso em: 10 jun. 2010. doi: 10.1023/ A: 1024632619171 .

PAGLIARINI, M.S. Citogenética aplicada ao melhoramento. In: NASS, L.L. et al. (Eds.). Recursos genéticos e melhoramento. Rondonópolis, MT: Fundação MT, 2001. p.871-910.

PORTER, D.R. et al. Inheritance of greenbug biotype G resistance in wheat. Crop Science, v.34, p.625-628, 1994. Disponível em: <https://www.crops.org/publications/cs/pdfs/34/ 3/CS0340030625>. Acesso em: 10 jun. 2010. doi: 10.2135/ cropsci1994.0011183X003400030004x.

PRETORIUS, Z.A. et al. Detection of virulence to wheat stem rust resistance gene $S r 31$ in Puccinia graminis f.sp. tritici in Uganda. Plant Disease, v.84, p.203, 2000. Disponível em: <http://apsjournals.apsnet.org/doi/abs/10.1094/ PDIS.2000.84.2.203B >. Acesso em: 20 abr. 2010. doi: 10.1094/PDIS.2000.84.2.203B.

REN, Z.L.; ZHANG, H.Q. Induction of small-segmenttranslocation between wheat and rye chromosomes. Science in China, v.27, n.3, p.323-331, 1997. Disponível em: <http:/ /www.ncbi.nlm.nih.gov/pubmed/18726334>. Acesso em: 10 jun. 2010. doi: 10.1007/BF02879094.

SARDESAI, N. et al. Identification and mapping of H32, a new wheat gene conferring resistance to Hessian Fly. Theoretical and Applied Genetics, v.111, p.1167-1173, 2005. Disponível em: <http://www.springerlink.com/content/10214171h6362016/ fulltext.pdf $>$. Acesso em: 20 abr. 2010. doi: 10.1007/s00122005-0048-6.

SEBESTA, E.E. et al. Registration of Amigo wheat germplasm resistant to greenbug. Crop Science, v.35, p.293, 1995. Disponível em: <https://www.crops.org/publications/cs/pdfs/35/ 1/CS0350010293>. Acesso em: 10 jun. 2010. doi: 10.2135/ cropsci1995.0011183X003500010074x.

SHIMIZU, Y. et al. Detection of the Sec- 1 locus of rye by a PCR-based method. Genes \& Genetics System, v.72, p.197203, 1997. Disponível em: <http://www.jstage.jst.go.jp/article/ ggs/72/4/197/_pdf>. Acesso em: 10 jun. 2010. doi: 10.1266/ ggs.72.197.

TAKETA, S.; TAKEDA, K. Production and characterization of a complete set of wheat - wild barley (Hordeum vulgare ssp. spontaneum ) chromosome addition lines. Breeding Science, 
v.51, p.199-206, 2001. Disponível em: <http://sciencelinks.jp/ j-east/article/200123/000020012301A0868146.php〉. Acesso em: 20 abr. 2010 . doi: 10.1270/jsbbs.51.199.

TANG, Z.X. et al. Characterization of three wheat cultivars possessing new 1BL.1RS wheat-rye translocations. Plant Breeding, v.128, p.524-527, 2009. Disponível em: <http:// onlinelibrary.wiley.com/doi/10.1111/j.1439-0523.2008.01598.x/ pdf >. Acesso em: 10 jun. 2010 . doi: 10.1111/j.14390523.2008.01598.x.

VILLAREAL, R.L. et al. Agronomic performance of chromosome 1B and T1BL.1RS near-isolines in the spring bread wheat Seri M82. Euphytica, v.103, p.195-202, 1998. Disponível em: <http://www.springerlink.com/content/rw1117663414n545/ fulltext.pdf $>$. Acesso em: 20 abr. 2010. doi: 10.1023/ A: 1018392002909

WEHLING, P. et al. Leaf-rust resistance in rye (Secale cereale L.). 1. Genetic analysis and mapping of resistance genes $\operatorname{Pr} 1$ and $P r 2$. Theoretical and Applied Genetics, v.107, p.432438, 2003. Disponível em: <http://www.springerlink.com/ content/xfpa4bbqgnqa8q67/fulltext.pdf $>$. Acesso em: 10 jun. 2010. doi: 10.1007/s00122-003-1263-7.

YAMAMOTO, M.; MUKAI, Y. High-resolution physical mapping of the secalin-1 locus of rye on extended DNA fibers. Cytogenetic and Genome Research, v.109, p.79-82, 2005. Disponível em: <http://content.karger.com/ProdukteDB/ produkte.asp? Aktion $=$ ShowPDF \&ArtikelNr $=82385 \&$ Ausgabe $=2306$ $10 \&$ ProduktNr $=224037 \&$ filename $=82385 . \mathrm{pdf}>$. Acesso em: 20. abr. 2010. doi:10.1159/000082385.

YAN, B.J. et al. Molecular cytogenetic identification of a new 1 RS/1BL translocation line with secalin absence. Hereditas (Beijing), v.27, p.513-517, 2005. Disponível em: <http:// view.ncbi.nlm.nih.gov/pubmed/16120568>. Acesso em: 20 abr. 2010. doi: CNKI:SUN:YCZZ.0.2005-04-003.

YANG, Z.J.; REN, Z.L. Expression of gene Pm8 for resistance to powdery mildew in wheat from Sichuan. Journal of
Sichuan Agriculture University, v.15, p.452-456, 1997. Disponível em: <http://epub.cnki.net/grid2008/docdown/ docdownload. asp $x$ ?filename $=$ SCND704.006 $\&$ dbcode $=$ CJFD $\& y e$ ar=1997\&dflag=pdfdown>. Acesso em: 20 abr. 2010.

YANG, Z.M. et al. Situation of the sources of stripe rust resistance of wheat in the post-CY32 era in China. Acta Agronomica Sinica, v.29, p.161-168, 2003. Disponível em: <ht tp://epub.cnki.net/grid2008/docdown/ docdownload.aspx?filename $=$ XBZW200302000 $\&$ dbcode $=$ CJFD $\&$ year $=2003 \&$ dflag $=$ pdfdown $>$. Acesso em: 10 jun. 2010. doi: cnki:ISSN:0496-3490.0.2003-02-000.

YU, J. et al. A draft sequence of the rice genome (Oryza sativa $\mathrm{L}$. ssp. indica). Science, v.296, p.79-92, 2002. Disponível em: <http://www.sciencemag.org/content/296/5565/79.full.pdf>. Acesso em: 20 abr. 2010. doi: 10.1126/science.1068037.

ZANNETTI, M.H.B.; LAUXEN, M.S. Alterações cromossômicas estruturais e numérias: consequências e aplicações. In: FREITAS, L.B.; BERED, F. (Orgs.). Genética e evolução vegetal. Porto Alegre: UFRGS, 2003. p.217-240.

ZHANG, W.J. et al. The identification and introgression of a powdery mildew resistant gene from rye chromosome 6R to wheat. Acta Genetica Sinica, v.26, n.5, p.563-570, 1999. Disponível em: <http://www.chinagene.cn/Jweb_jgg/EN/abstract/ abstract18880.shtml>. Acesso em: 20 abr. 2010.

ZHAO, H.X. et al. H22, a major resistance gene to the Hessian Fly (Mayetiola destructor), is mapped to the distal region of wheat chromosome 1DS. Theoretical and Applied Genetics, v.113, p.1491-1496, 2006. Disponível em: <http://www.springerlink.com/ content/w22658p65u31771r/fulltext.pdf >. Acesso em: 20 abr. 2010. doi: 10.1007/s00122-006-0396-x.

ZHOU, Y. et al. Utilization of 1BL/1RS translocation in wheat breeding in china. Acta Agronomica Sinica, v.30, p.531-535, 2004. Disponível em: <http://epub.cnki.net/grid2008/docdown/ docdownload.aspx ?filename $=$ XBZW200406002 $\&$ dbcode $=$ CJFD \&year=2004\&dflag=pdfdown $>$. Acesso em: 20 abr. 2010. 